\title{
Overnight dexamethasone suppression of cortisol is associated with radiocholesterol uptake patterns in adrenal incidentalomas
}

\author{
Luisa Barzon, Francesco Fallo, Nicoletta Sonino and Marco Boscaro ${ }^{1}$ \\ Department of Medical and Surgical Sciences, Division of Endocrinology, University of Padova, Italy and ${ }^{1}$ Department of Internal Medicine, \\ Division of Endocrinology, University of Ancona, Italy \\ (Correspondence should be addressed to Francesco Fallo, Department of Medical and Surgical Sciences, Division of Endocrinology, University of Padova, \\ via Ospedale 105, 35128 Padova, Italy; Email: francesco.fallo@unipd.it)
}

Low-dose dexamethasone suppression is considered to be the most accurate test for diagnosing subclinical hypercortisolism (1-3). The recommended cut-off point for excluding the presence of Cushing's syndrome is a morning plasma cortisol concentration of less than $50 \mathrm{nmol} / \mathrm{l}$ after $1 \mathrm{mg}$ dexamethasone. We read, with interest, the article by Valli et al. (4), who assessed the value of endocrine testing, as opposed to radiocholesterol scintigraphy, in diagnosing subclinical cortisol hypersecretion in a series of incidentally discovered adrenocortical adenomas. Patients showing unilateral uptake by their adrenal mass at scintigraphy had significantly lower adrenocorticotrophin levels, higher midnight levels of plasma cortisol, abnormalities of the cortisol diurnal rhythm, and higher cortisol concentrations after overnight administration of $1 \mathrm{mg}$ and (i.v.) $4 \mathrm{mg}$ dexamethasone than did patients with bilateral uptake. The sensitivity of the overnight $1 \mathrm{mg}$ dexamethasone suppression test improved to $100 \%$ when the cut-off point for the morning plasma cortisol level was set at $60 \mathrm{nmol} / \mathrm{l}$, rather than the classical value of $138 \mathrm{nmol} / \mathrm{l}$.

In our population of patients with adrenal incidentaloma (5), we re-evaluated the accuracy of the $1 \mathrm{mg}$ overnight dexamethasone suppression test by comparing the new cut-off point for plasma cortisol $(50 \mathrm{nmol} / \mathrm{l}$ at $0800 \mathrm{~h}$ the following day) with adrenocortical scintigraphy. Out of 284 consecutive patients, 83 with unilateral scintigraphic uptake and histological diagnosis of adrenocortical adenoma were selected. Adrenal scintiscans were performed using $11-14 \mathrm{MBq}$ $\left[{ }^{75}\right.$ Se]-Selenio-6 $\alpha$-methyl-19norcholesterol (Scintadren; Amersham, Buckinghamshire, UK). Images were acquired at $72-120 \mathrm{~h}$ following tracer injection. Scintigraphic evaluation demonstrated various patterns of uptake: (i) exclusive uptake by the tumor without visualization of the contralateral gland (36 subjects); (ii) prevalent uptake by the tumor with visualization of the contralateral gland (28 subjects); (iii) bilateral symmetrical uptake (19 subjects). The results of the overnight dexamethasone suppression test demonstrated a strong association with scintigraphic uptake, and a continuous spectrum in adrenal autonomy (Table 1). Moreover, all patients with plasma cortisol levels above $138 \mathrm{nmol} / \mathrm{l}$ after dexamethasone showed exclusive uptake at scintigraphy. With a plasma cortisol cut-off point of $138 \mathrm{nmol} / \mathrm{l}$, the sensitivity and specificity of the overnight dexamethasone suppression test for identifying subclinical cortisol-secreting adenomas (exclusive uptake) were $44 \%$ and $100 \%$ respectively. With a lowering of the cut-off point to $50 \mathrm{nmol} / \mathrm{l}$, the sensitivity improved to $75 \%$, but the specificity fell to $72 \%$. Although the sensitivity of the test was lower in our experience, our data are in agreement with those of Valli et al. (4), confirming the usefulness of $1 \mathrm{mg}$ overnight dexamethasone suppression, with revised criteria, as a screening test for subclinical hypercortisolism in patients with adrenal incidentaloma.

Table 1 Relationship between radiocholesterol uptake and morning plasma cortisol levels after administration of $1 \mathrm{mg}$ dexamethasone overnight in 83 patients with unilateral adrenal incidentaloma.

\begin{tabular}{lccc}
\hline & \multicolumn{2}{c}{ Morning levels of plasma cortisol after $\mathbf{1 ~ m g ~ d e x a m e t h a s o n e ~ o v e r n i g h t ~}$} \\
\cline { 2 - 4 } Scintigraphic uptake & $\begin{array}{c}\text { No. of subjects }(\%) \\
(<50 \mathrm{nmol} /)^{*}\end{array}$ & $\begin{array}{c}\text { No. of subjects }(\%) \\
(50-138 \mathrm{nmol} / /)^{*}\end{array}$ & $\begin{array}{c}\text { No. of subjects }(\%) \\
(>138 \mathrm{nmol} /)^{*}\end{array}$ \\
\hline Exclusive $(n=36)$ & $9(25)$ & $11(31)$ & $16(44)$ \\
Prevalent $(n=28)$ & $16(57)$ & $12(43)$ & 0 \\
Symmetrical $(n=19)$ & $16(84)$ & $3(16)$ & 0 \\
\hline
\end{tabular}

${ }^{*}$ Scintigraphic uptake versus postdexamethasone plasma cortisol: $P<0.0001, \chi^{2}$ test. 


\section{References}

1 Boscaro M, Barzon L, Fallo F \& Sonino N. Cushing's syndrome. Lancet 2001357 783-791.

2 Barzon L \& Boscaro M. Diagnosis and management of adrenal incidentalomas. Journal of Urology $2000 \mathbf{1 6 3} 398-407$.

3 Reinke M. Subclinical Cushing's syndrome. Endocrinology and Metabolism Clinics of North America 200029 43-56.

4 Valli A, Catargi B, Ronci N, Vergnot V, Leccia F, Ferriere JM et al. Biochemical screening for subclinical cortisol-secreting adenomas amongst adrenal incidentalomas. European Journal of Endocrinology 20018 401-408.

5 Barzon L, Scaroni C, Sonino N, Fallo F, Gregianin M, Macrì C et al. Incidentally discovered adrenal tumors: endocrine and scintigraphic correlates. Journal of Clinical Endocrinology and Metabolism 199883 55-62.

Received 20 April 2001

Accepted 27 April 2001 